Research Article

\title{
Catalytic CO Methanation over Mesoporous ZSM5 with Different Metal Promoters
}

\section{Lee Peng Teh ${ }^{1 *}$, Sugeng Triwahyono², Aishah Abdul Jalil ${ }^{3,4}$, Herma Dina Setiabudi ${ }^{5,6}$, Muhammad Arif Ab Aziz ${ }^{3,7}$}

\author{
${ }^{1}$ Centre for Advanced Materials and Renewable Resources, Faculty of Science and Technology, Universiti \\ Kebangsaan Malaysia, 43600 UKM Bangi, Selangor, Malaysia \\ ${ }^{2}$ Department of Chemistry, Faculty of Science, Universiti Teknologi Malaysia, \\ 81310 UTM Johor Bahru, Johor, Malaysia \\ ${ }^{3}$ Department of Chemical Engineering, Faculty of Chemical and Energy Engineering, \\ Universiti Teknologi Malaysia, 81310 UTM Johor Bahru, Johor, Malaysia \\ ${ }^{4}$ Centre of Hydrogen Energy, Institute of Future Energy, Universiti Teknologi Malaysia, \\ 81310 UTM Johor Bahru, Johor, Malaysia \\ ${ }_{5}^{5}$ Faculty of Chemical and Natural Resources Engineering, Universiti Malaysia Pahang, \\ 26300 Gambang, Kuantan, Pahang, Malaysia \\ ${ }^{6}$ Centre of Excellence for Advanced Research in Fluid Flow, Universiti Malaysia Pahang, \\ 26300 Gambang, Kuantan, Pahang, Malaysia \\ ${ }^{7}$ Sustainable Waste Management Research Group, Universiti Teknologi Malaysia \\ 81310 UTM Johor Bahru, Johor, Malaysia
}

Received: $15^{\text {th }}$ November 2018; Revised: $16^{\text {th }}$ January 2019; Accepted: $17^{\text {th }}$ January 2019; Available online: 25th January 2019; Published regularly: April 2019

\begin{abstract}
The carbon monoxide methanation has possessed huge potential as an effective method to produce synthetic natural gas (SNG). The basic requirements such as high catalytic activity at low temperatures $\left(<500{ }^{\circ} \mathrm{C}\right)$ and high stability throughout all temperatures is needed for an ideal methanation catalysts. The ultimate goal of the study is to examine the influential of different metal promoters towards catalytic properties and catalytic CO methanation performance. A series of metal promoters (Rh, Co, Pd and Zn) mesoporous ZSM5 were synthesized using an incipient-wetness impregnation method and evaluated for catalytic CO methanation. XRD analysis showed that only metal oxides and no metallic phase of $\mathrm{Rh}, \mathrm{Co}, \mathrm{Pd}$, and $\mathrm{Zn}$ were observed. The nitrogen physisorption analysis showed that mZSM5 possessed high surface area and micro-mesoporosity with intra- and interparticle pores. FESEM analysis illustrated that mZSM5 had typical coffin-type morphology and Rh metal dispersed on the surface of the support was confirmed by EDX analysis. Moreover, $\mathrm{Rh}\left(\mathrm{CO}\right.$ conversion $=95 \%, \mathrm{CH}_{4}$ yield $\left.=82 \%\right)$ and $\mathrm{Co}(\mathrm{CO}$ conversion $=91 \%, \mathrm{CH}_{4}$ yield $=71 \%$ ) promoters showed significant improvement in $\mathrm{CO}$ methanation. On the other hand, $\mathrm{Pd}\left(\mathrm{CO}\right.$ conversion $=18 \%, \mathrm{CH}_{4}$ yield $\left.=12 \%\right)$ and $\mathrm{Zn}\left(\mathrm{CO}\right.$ conversion $=10 \%, \mathrm{CH}_{4}$ yield $\left.=9 \%\right)$ promoters had only low benefit to the CO methanation. This study affirmed that the catalytic activity of CO methanation was influenced by the variation in the type of metal loading due to different nature of metallic phases and their synergistic interaction with the supporting material. Copyright (C) 2019 BCREC Group. All rights reserved
\end{abstract}

Keywords: Synthetic Natural Gas, CO Methanation, Mesoporous ZSM5, Metal Promoters, Rh

How to Cite: Teh, L.P., Triwahyono, S., Jalil, A.A., Setiabudi, H.D., Aziz, M.A.A. (2019). Catalytic CO Methanation over Mesoporous ZSM5 with Different Metal Promoters. Bulletin of Chemical Reaction Engineering \& Catalysis, 14 (1): 228-237 (doi:10.9767/bcrec.14.1.3618.228-237)

Permalink/DOI: https://doi.org/10.9767/bcrec.14.1.3618.228-237

\section{Introduction}

Recent years, CO methanation has gained

\footnotetext{
* Corresponding Author.

E-mail: lpteh@ukm.edu.my (L.P. Teh)
}

widespread attention in the production of synthetic natural gas (SNG) and appeared to be a promising approach due to growing demand for natural gas as an important future energy carrier $[1,2]$. The $\mathrm{CO}$ methanation reaction occurs as follows $[3,4]$ : 


$$
\begin{aligned}
3 \mathrm{H}_{2}+\mathrm{CO} \rightarrow \mathrm{CH}_{4}+\mathrm{H}_{2} \mathrm{O} \\
\Delta \mathrm{H}_{298 \mathrm{~K}}=-206.1 \mathrm{kJmol}^{-1}
\end{aligned}
$$

In $\mathrm{CO}$ methanation, nickel-based catalysts [5-7] are undeniably known as the reference for methanation benchmark. Unfortunately, the highly exothermic nature of the methanation reaction have resulted in $\mathrm{Ni}$ sintering and carbon formation. Therefore, it is urgent need to design and develop new material for $\mathrm{CO}$ methanation as the alternative for the wellestablished Ni-based catalysts. It is noteworthy that supporting material played a significant role on the catalytic performance. Mesoporous zeolite is a type of material, which is the combination of microporous structure with additional intracrystalline or intercrystalline mesoporous. It demonstrated excellent catalytic activity in alkylation and cracking [8], methanol-to-olefins (MTO) [9-10], adsorption reaction [11] and $\mathrm{CO}_{2}$ capture [12]. Gua et al. studied $\mathrm{CO}_{2}$ methanation over mesoporous Ni/ZSM5, Ni/SBA-15, $\mathrm{Ni} / \mathrm{MCM}-41, \mathrm{Ni} / \mathrm{Al}_{2} \mathrm{O}_{3}$ and $\mathrm{Ni} / \mathrm{SiO}_{2}$. The presence of basic property and the metal-support synergistic effect is the main reason of Ni/ZSM5 as the most active methanation catalyst among all the mesoporous supports. Moreover, it also presented superb anti-coking and antisintering properties [13]. Therefore, mesoporous ZSM5 (mZSM5) can be a better alternative for CO methanation.

Besides, it is well known that different metal promoters exhibited different catalytic properties and performance. In literatures, the effective and convenient way to improve the catalytic methanation activity is by addition of metal promoters [14-15]. Furthermore, it should be noted that the rate controlling step in CO methanation is believed to be CO dissociation in which this dissociation step is structuresensitive dependent and happen on metallic phase [16]. Panagiotopoulou [17] studied hydrogenation of $\mathrm{CO}_{2}$ over $\mathrm{Rh} / \mathrm{TiO}_{2}, \mathrm{Ru} / \mathrm{TiO}_{2}, \mathrm{Pt} / \mathrm{TiO}_{2}$ and $\mathrm{Pd} / \mathrm{TiO}_{2}$ catalysts. They reported that catalytic methanation activity of $\mathrm{Rh}$ catalyst is more active than Ru catalyst. On the contrary, $\mathrm{Pd}$ and $\mathrm{Pt}$ catalyst are practically inactive. The results significantly depend on the nature of the metallic phase. Zhang et al. [18] studied the promotional effect of cobalt on $\mathrm{MoS}_{2}$ catalyst for CO methanation using a density functional study. It is noted that cobalt metal demonstrated promoting effects on the $\mathrm{MoS}_{2}$ and provided easiness of $\mathrm{OH}$ species removal for continuous vacant of active sites which can be always available for further adsorption and interaction. Martin et al. [19] examined the structure-function relationship of $\mathrm{Rh} / \mathrm{Al}_{2} \mathrm{O}_{3}$ and
$\mathrm{Rh} / \mathrm{SiO}_{2}$ towards $\mathrm{CO}_{2}$ methanation. They found that the dissociation of $\mathrm{CO}_{2}$ led to minor formation of $\mathrm{RhO}_{\mathrm{x}}$ is the reason for the enhanced activity in $\mathrm{Rh} / \mathrm{Al}_{2} \mathrm{O}_{3}$ catalyst. But, it is noteworthy that the existing metal promoters still suffered from deactivation because of low surface area of support material and low dispersion of loaded metal, which can be avoidable by choosing a suitable supported metal material [20].

In the contemporary work, we examined the comparative study for CO methanation over a series of metals ( $\mathrm{Rh}, \mathrm{Co}, \mathrm{Pd}$, and $\mathrm{Zn}$ ) supported on mesoporous ZSM5 (mZSM5). The selection of the metals was based on the potential basis to replace the existing Ni-based catalysts. Rhodium and palladium were proposed as the noble metal's candidates. On the other hand, cobalt and zinc are representative of non-noble metals. Although these metals have been studied over a variety of supports, but to the best of our knowledge, the approach to introduce these metals onto mZSM5 have not been reported before. In the current work, the influence of the different metals in the physicochemical properties of mZSM5 and their catalytic performance are presented and discussed. Various techniques including XRD, $\mathrm{N}_{2}$ physisorption, FTIR, FESEM were used to characterize the structural, textural and morphology of the catalysts. The $\mathrm{CO}$ conversion and the products yield $\left(\mathrm{CH}_{4}\right.$ and $\mathrm{CO}_{2}$ ) were investigated.

\section{Materials and Methods}

\subsection{Materials}

Tetrapropylammonium bromide (TPA-Br, $98 \%$ ), benzalkonium chloride ( $\geq 95 \%$ ), rhodium(III) chloride $\left(\mathrm{RhCl}_{3}, 98 \%\right)$, cobalt(II) acetate tetrahydrate $\left(\mathrm{Co}\left(\mathrm{C}_{2} \mathrm{H}_{3} \mathrm{O}_{2}\right)_{2}\left(\mathrm{H}_{2} \mathrm{O}\right)_{4}, \geq 98 \%\right)$, palladium(II) chloride $\left(\mathrm{PdCl}_{2}, 99 \%\right)$ and zinc nitrate hexahydrate $\left(\mathrm{Zn}\left(\mathrm{NO}_{3}\right)_{2} .6 \mathrm{H}_{2} \mathrm{O}, 98 \%\right)$ were purchased from Sigma Aldrich. Sodium hydroxide $(\mathrm{NaOH}, \geq 97 \%)$, Aluminium hydroxide $\left(\mathrm{Al}(\mathrm{OH})_{3}, \geq 99 \%\right)$ and tetraethyl orthosilicate (TEOS, $\geq 99 \%$ ) were obtained from Merck Sdn. Bhd., Malaysia. All chemicals were used as received without further purification.

\subsection{Preparation of Catalysts}

The mesoporous ZSM5 was prepared by dual templating method using tetrapropylammonium bromide (TPA-Br) as micropore directing agent and benzalkonium chloride as mesopore directing agent [21]. The starting parameters are $\mathrm{Si} / \mathrm{Al}=22.90, \mathrm{H}_{2} \mathrm{O} / \mathrm{Si}=18.30$, $\mathrm{TPA}-\mathrm{Br} / \mathrm{Si}=0.17$, benzalkonium chloride/Si $=$ 0.06 and $\mathrm{NaOH} / \mathrm{Si}=0.15$. Firstly, the mixture 
of benzalkonium chloride, tetrapropylammonium bromide (TPA-Br), sodium hydroxide $(\mathrm{NaOH})$ and distilled water $\left(\mathrm{H}_{2} \mathrm{O}\right)$ was homogeneously mixed at room temperature under stirring speed $1000 \mathrm{rpm}$ for $5 \mathrm{~min}$. Then, aluminium hydroxide, $\mathrm{Al}(\mathrm{OH})_{3}$ and tetraethyl orthosilicate (TEOS), $\mathrm{Si}\left(\mathrm{OC}_{2} \mathrm{H}_{5}\right)_{4}$ was added and homogeneously mixed at room temperature under stirring speed $1000 \mathrm{rpm}$ for $3 \mathrm{~h}$. After that, the mixture was transferred into autoclave and maintained at $423 \mathrm{~K}$ for 5 days. The product was washed, filtered and drying at $383 \mathrm{~K}$ for 3 $\mathrm{h}$. The as-synthesized catalyst was calcined at $823 \mathrm{~K}$ for $3 \mathrm{~h}$. For metal-promoted mZSM5, they were prepared by impregnation of mZSM5 with an aqueous solution of the corresponding metal salt precursor ( $\mathrm{RhCl}_{3}$, $\mathrm{Co}\left(\mathrm{C}_{2} \mathrm{H}_{3} \mathrm{O}_{2}\right)_{2}\left(\mathrm{H}_{2} \mathrm{O}\right)_{4}, \mathrm{PdCl}_{2}, \mathrm{Zn}\left(\mathrm{NO}_{3}\right)_{2} .6 \mathrm{H}_{2} \mathrm{O}$. The resulting slurry was heated slowly at $353 \mathrm{~K}$ under continuous stirring and maintained at that temperature until nearly all the water being evaporated. The solid residue was dried in an oven at $383 \mathrm{~K}$ overnight before calcination at $823 \mathrm{~K}$ for $3 \mathrm{~h}$. The metal loading of the catalysts chosen was 5 wt\%, which is continuity from our previous study. Besides, we chosen 5 wt\% metal loading also due to balance between activity and economic reason of noble and nonnoble metals. All metal-promoted mZSM5 were denoted as Rh/mZSM5, Co/mZSM5, $\mathrm{Pd} / \mathrm{mZSM} 5$, and Zn/mZSM5.

\subsection{Characterization of Catalysts}

The crystalline structure of the catalyst was studied by X-ray diffraction (XRD) recorded on a powder diffractometer $(40 \mathrm{kV}, 40 \mathrm{~mA})$ using

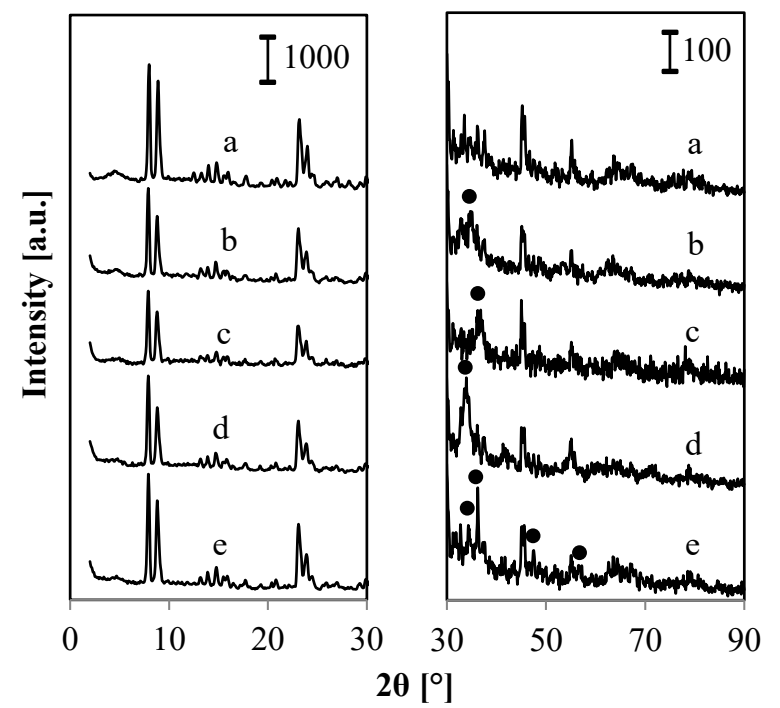

Figure 1. X-ray diffraction patterns of (a) mZSM5, (b) Rh/mZSM5, (c) Co/mZSM5, (d) $\mathrm{Pd} / \mathrm{mZSM} 5$, and (e) Zn/mZSM5. $(\bullet)=$ metal oxides
$\mathrm{Cu}-\mathrm{K} \alpha$ radiation source in the range of $2 \theta=2$ $90^{\circ}$ with a scan rate of $0.1^{\circ}$ continuously. The nitrogen physisorption analysis of the catalysts was carried out by using a Beckman Coulter SA 3100. Prior to the measurement, approximately $0.05 \mathrm{~g}$ of catalyst was put into a sample tube holder, followed by evacuation at $573 \mathrm{~K}$ for $1 \mathrm{~h}$. Then, adsorption of nitrogen was carried out at $77 \mathrm{~K}$. Surface area, pore size distributions and pore volumes were determined from the sorption isotherms using a non-local density functional theory (NLDFT) method. FTIR spectra of the fresh catalysts were acquired on Agilent Cary640 FTIR Spectrometer using the $\mathrm{KBr}$ method with a scan range of 400-4000 $\mathrm{cm}^{-1}$. The surface morphology and EDX analysis of the samples was performed using FESEM-EDX (JEOL JSM-6701F) with an accelerating voltage of $5 \mathrm{kV}$.

\subsection{Catalytic Performance of CO Methanation}

CO methanation was conducted in a microcatalytic quartz reactor at atmospheric pressure at temperature range of $150-450{ }^{\circ} \mathrm{C}$. The thermocouple was directly inserted into the catalyst bed to measure the actual pretreatment and reaction temperatures. Initially, 0.2 $\mathrm{g}$ of catalyst were treated in an oxygen stream for $1 \mathrm{~h}$ followed by a hydrogen stream for $3 \mathrm{~h}$ at $773 \mathrm{~K}$ and cooled down to the desired reaction temperature in a hydrogen stream. When the temperature became stable, a mixture of $\mathrm{H}_{2}$ and $\mathrm{CO}$ was fed into the reactor at a specific gas hourly space velocity (GHSV) of $13,500 \mathrm{~mL}$ $\mathrm{g}^{-1} \cdot \mathrm{h}^{-1}$ and $\mathrm{H}_{2} / \mathrm{CO}$ mass ratio of $8 / 1$. The composition of the outlet gases was analyzed by an online $6090 \mathrm{~N}$ Agilent gas chromatograph equipped with a GS-Carbon PLOT column and a TCD detector. The $\mathrm{CO}$ conversion and yield of $\mathrm{CH}_{4}$ and $\mathrm{CO}_{2}$ were calculated in equation (2-4) as below:

$$
\begin{aligned}
& C O \text { conversion (\%) }=\frac{M_{\mathrm{CH}_{4}}+M_{\mathrm{CO}_{2}}}{M_{\mathrm{CO}+M_{\mathrm{CH}_{4}}+M_{\mathrm{CO}_{2}}}} \times 100 \\
& \mathrm{CH}_{4} \text { yield }(\%)=\frac{M_{\mathrm{CH}_{4}}}{M_{\mathrm{CO}}+M_{\mathrm{CH}_{4}}+M_{\mathrm{CO}_{2}}} \times 100 \\
& \mathrm{CO}_{2} \text { yield }(\%)=\frac{M_{\mathrm{CO}_{2}}}{M_{\mathrm{CO}}+M_{\mathrm{CH}_{4}}+M_{\mathrm{CO}_{2}}} \times 100
\end{aligned}
$$

where, $M_{c o}, M_{C_{3}}$, and $M_{C O_{2}}$ is the mole of the CO, $\mathrm{CH}_{4}$, and $\mathrm{CO}_{2}$, respectively.

\section{Result and Discussion}

3.1 Physicochemical Properties of Catalysts

Figure 1 shows the XRD diffraction analysis 
of all the catalysts. The XRD results show the typical diffraction peaks at $2 \theta=7-10^{\circ}$ and 22 $25^{\circ}$, which also presented in typical MFI type zeolite [21]. The introduction of the metals did not shift the peaks position, but the intensities of the peaks were slightly decreased as compared to the bare mZSM5. However, the characteristic diffraction peaks of ZSM-5 still remained.

The broad peak at $2 \theta=34.5^{\circ}$ was observed on $\mathrm{Rh} / \mathrm{mZSM} 5$, which is assigned to (114) peak for $\mathrm{Rh}_{2} \mathrm{O}_{3}$ particles in an orthorhombic structure [22]. The high dispersion of Rh species was confirmed by the absence of other Rhcontaining crystal phases. Vita et al. [23] reported that no evidence for the existence of rhodium phase (elemental rhodium and/or Rh oxides) on $\mathrm{CeO}_{2}$ was observed because of low loading amount and well-dispersed $\mathrm{Rh}$ metal on the support. A peak at $2 \theta=37^{\circ}$ was observed on Co/mZSM5, which is a characteristic peak of crystalline $\mathrm{Co}_{3} \mathrm{O}_{4}$, as reported by $\mathrm{Li}$ et al. [24] and Díez-Ramírez et al. [25]. Some of the peak for Co oxides may be overlapped with the peak of mZSM5, and thus, no peak of metallic Co was observed. For Pd/mZSM5, a sharp diffraction peak which assigned to $\mathrm{PdO}$ was observed at $2 \theta=34^{\circ}$. But, no diffraction peak at $2 \theta=40^{\circ}$ and $46^{\circ}$, which attributed to metallic $\mathrm{Pd}$ was observed [26-27]. Similar result was reported by Adams et al. [28] whereby no diffraction peaks assigned to $\mathrm{Pd}$ species were detected on the $\mathrm{TiO}_{2}, \mathrm{SiO}_{2}$ and $\mathrm{Al}_{2} \mathrm{O}_{3}$ supports due to the small amount and well distribution $\mathrm{Pd}$ species on the surface of the support. Furthermore, several peaks at $2 \theta=34.5^{\circ}(002), 36.3^{\circ}(101)$, $47.6^{\circ}(102)$, and $56.7^{\circ}(110)$, which are characteristic peaks of $\mathrm{ZnO}$ wurtzite structure were observed on Zn/mZSM5 [29]. In brief, the XRD results indicated that no significance structural degradation was observed after metal introduction and the impregnated metals (Rh, Co, $\mathrm{Pd}$ and $\mathrm{Zn}$ ) are mainly exists as metal oxides form.

The nitrogen physisorption was employed to depict the porosity of the material. Figure 2 demonstrated the nitrogen physisorption isotherms of the metal-promoted mZSM5 catalysts. The presence of micropores was affirmed by nitrogen uptake at low relative pressure. According to IUPAC classification, all catalysts exhibited isotherms with type IV pattern and H1 hysteresis loops, signifying the characteristic of mesoporous materials. It showed coexistence of micro-mesoporosity properties in the material. Moreover, 2 pronounced steps occurred at $P / P_{0}=0.2-0.4$ and $0.9-1.0$, which attributed to capillary condensation of the intraparticles pores and interparticles pores, respectively [30]. The results revealed a significantly increased in mesopores in $\mathrm{Rh} / \mathrm{mZSM} 5$, as demonstrated by the adsorption behavior in $\mathrm{N}_{2}$ adsorption-desorption isotherm. It is probably due to the presence of external surface $R h$ particles which may causing blockage of the original pores structure and created bigger pores. This also have led to the increased in intraparticle pores and total pore volume in $\mathrm{Rh} / \mathrm{mZSM} 5$. The same phenomenon was also observed in metal loaded onto aluminophosphate, which led to an increased in the adsorption-desorption volume probably due to the formation of mesoporous structure [31]. Besides, Bautista et al. [32] claimed that the behavior in dissimilarity of the mesopore size is attributed to the continuous pores restructuring of the material.
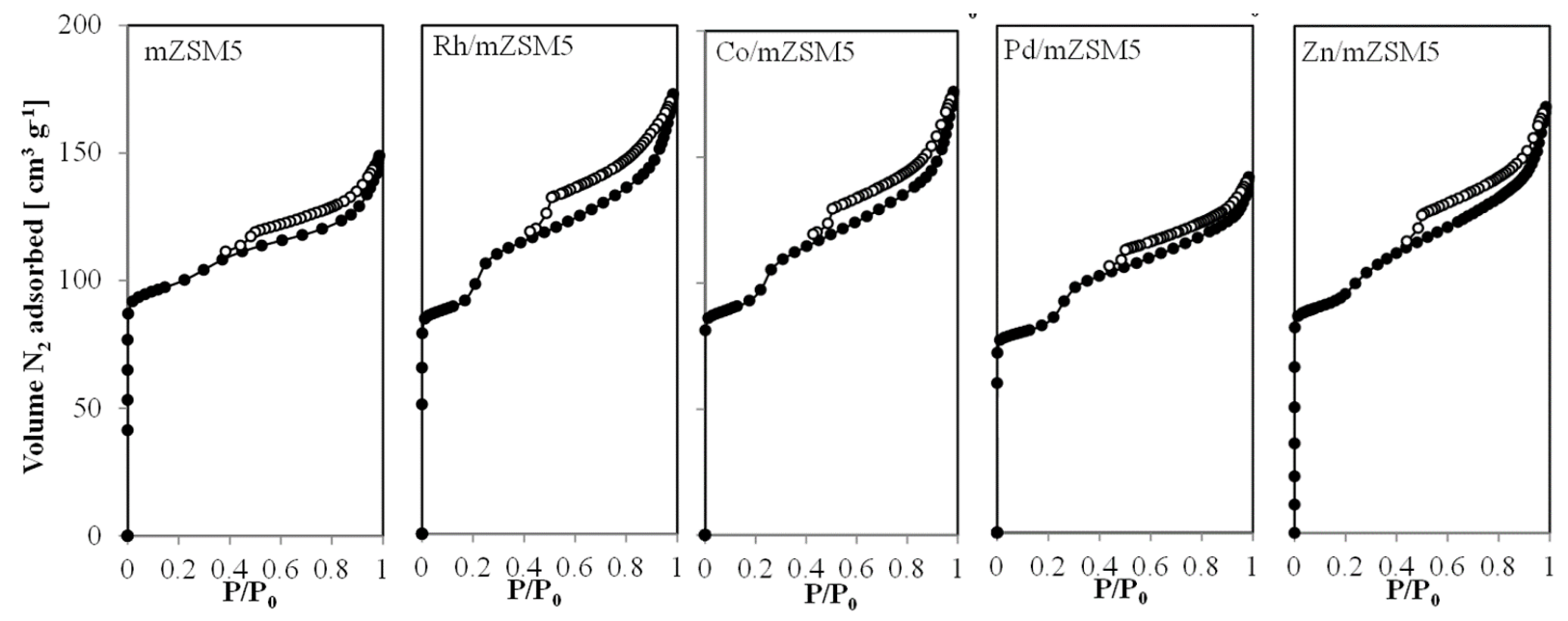

Figure 2. Nitrogen physisorption isotherms of the catalysts. 
Figure 3 demonstrated NLDFT pore size distribution of the catalysts. All catalysts demonstrated pore size distribution in the range of $<20 \AA$ and 35-70 A. It can be observed that the introduction of metals altered the pore size distribution of the catalysts. The high number of pores at $\sim 35 \AA$ was observed for Pd/mZSM5, might be due to the pore blockage by Pd metal loading. Besides, Zn/mZSM5 showed an obviously decreased in the pores at $\sim 40 \AA$, with the simultaneously increased the pores at $\sim 12 \AA$.

Table 1 summarizes the textural properties of the catalysts. The surface area of mZSM5, Rh/mZSM5, Co/mZSM5, Pd/mZSM5, and $\mathrm{Zn} / \mathrm{mZSM} 5$ are $857,642,594,520$, and 674 $\mathrm{m}^{2} \cdot \mathrm{g}^{-1}$, respectively. In addition, the total pore volume of mZSM5, Rh/mZSM5, Co/mZSM5, $\mathrm{Pd} / \mathrm{mZSM} 5$, and $\mathrm{Zn} / \mathrm{mZSM} 5$ are $0.2303,0.2580$, $0.2610,0.2090$, and $0.2530 \mathrm{~cm}^{3} \cdot \mathrm{g}^{-1}$, respectively. It can be concluded that introduction of the metals led to the decrease in surface area. In addition, two different trends of total pore volumes were observed: total pore volume increased after introduction of $\mathrm{Rh}, \mathrm{Co}$, and $\mathrm{Zn}$. Meanwhile, it is decreased with Pd loading. It can be postulated that the location of loaded $\mathrm{Rh}, \mathrm{Co}$, and $\mathrm{Zn}$ is on the exterior part of the mZSM5. On the other hand, Pd located in the inner of the mZSM5 pores. It is noteworthy that suitable textural properties are believed to

Table 1. Physicochemical properties of the mZSM5-based catalysts

\begin{tabular}{lcc}
\hline Adsorbents & $\begin{array}{c}\text { Surface area } \\
\left(\mathrm{m}^{2} \cdot \mathrm{g}^{-1}\right)\end{array}$ & $\begin{array}{c}\text { Total pore volume } \\
\left(\mathrm{cm}^{3} \cdot \mathrm{g}^{-1}\right)\end{array}$ \\
\hline mZSM5 & 857 & 0.2303 \\
Rh/mZSM5 & 642 & 0.2580 \\
Co/mZSM5 & 594 & 0.2610 \\
Pd/mZSM5 & 520 & 0.2090 \\
Zn/mZSM5 & 674 & 0.2530 \\
\hline
\end{tabular}

be one of the factors for excellent catalytic activity by providing higher exposure of the active metal-reactant gases interactions and improved the reactant-product diffusion efficiency.

The examination of the functional groups in the catalyst was done by FTIR analysis. Figure 4 displays the FTIR spectra in the range of 4000-400 $\mathrm{cm}^{-1}$ for fresh metal-promoted mZSM5 catalysts. The stretching vibration of hydroxyl group and bending vibration of water molecules were presented in the band at 3460 $\mathrm{cm}^{-1}$ and $1680 \mathrm{~cm}^{-1}$, respectively. The absorption region of zeolite is shown in the region of 1300-400 $\mathrm{cm}^{-1}$, due to the presence of $\mathrm{SiO}_{4}$ and $\mathrm{AlO}_{4}$ tetrahedron units. The characteristic band of the external and internal asymmetric stretching vibration were located at $1280 \mathrm{~cm}^{-1}$ and $1150 \mathrm{~cm}^{-1}$, respectively. Moreover, the presence of external symmetric stretching was

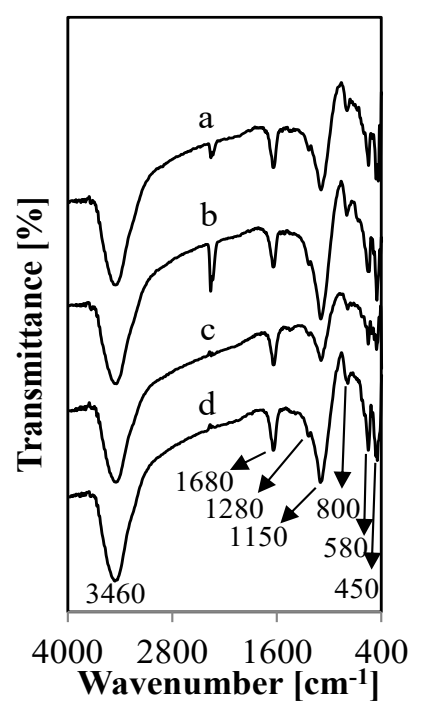

Figure 4. FTIR spectra of (a) Rh/mZSM5, (b) Co/mZSM5, (c) Pd/mZSM5, and (d) Zn/mZSM5 fresh catalysts in the region of 4000-400 $\mathrm{cm}^{-1}$.
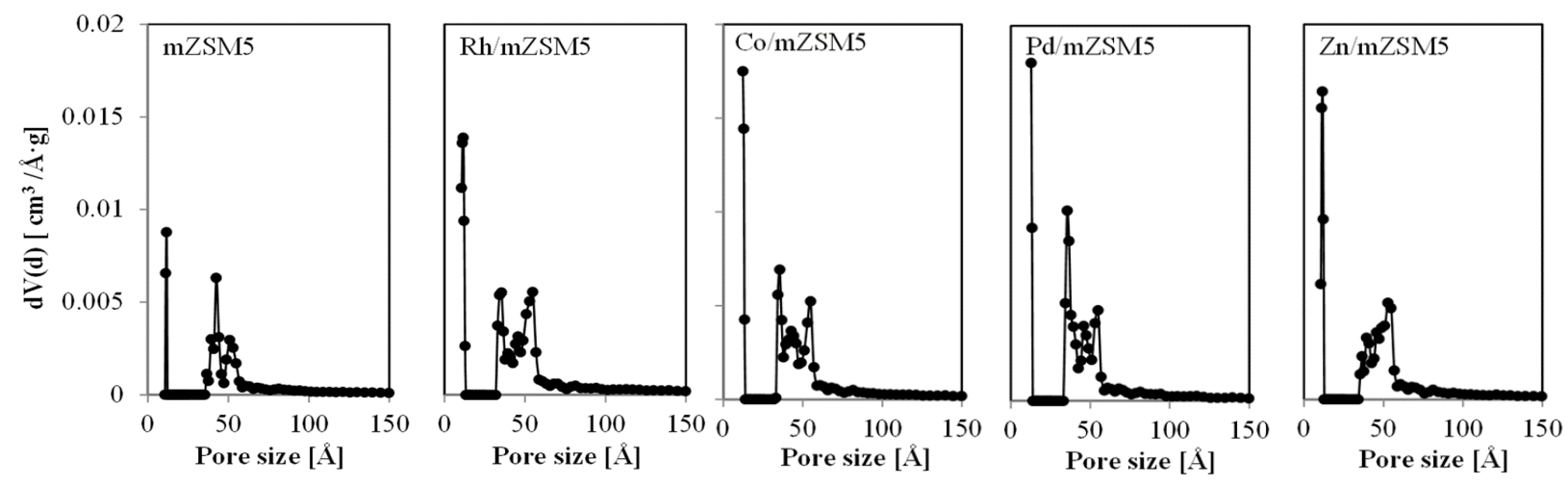

Figure 3. NLDFT Pore size distribution of the catalysts. 
showed in a small band at $800 \mathrm{~cm}^{-1}$. Two sharp bands were observed at $580 \mathrm{~cm}^{-1}$ and $450 \mathrm{~cm}^{-1}$ can be ascribed to the framework double four membered ring vibration and T-O bending vibration (Si-O and Al-O) of MFI type zeolites [33-34]. The FTIR results showed no shifting in the peak positions for metal-loaded mZSM5 catalysts as compared with the bare mZSM5 (not shown), indicating there is no structural framework difference present in the catalysts.

Figure 5 illustrates FESEM images and EDX analysis of mZSM5 and Rh/mZSM5. Both mZSM5 and Rh/mZSM5 demonstrated coffinshaped morphology. The mZSM5 showed a smooth surface morphology while some of Rh particles were dispersed on the mZSM5 surface was observed for Rh/mZSM5. To confirm the presence of $\mathrm{Rh}$ on the surface of the support, EDX analysis was carried out. From the analysis, it confirmed the approximately $5 \mathrm{wt} \%$ of $\mathrm{Rh}$ loading on mZSM5 support.

\subsection{CO Methanation Performance}

Figure 6 shows the catalytic performance results for all the catalyst in $150-450{ }^{\circ} \mathrm{C}$. At 450
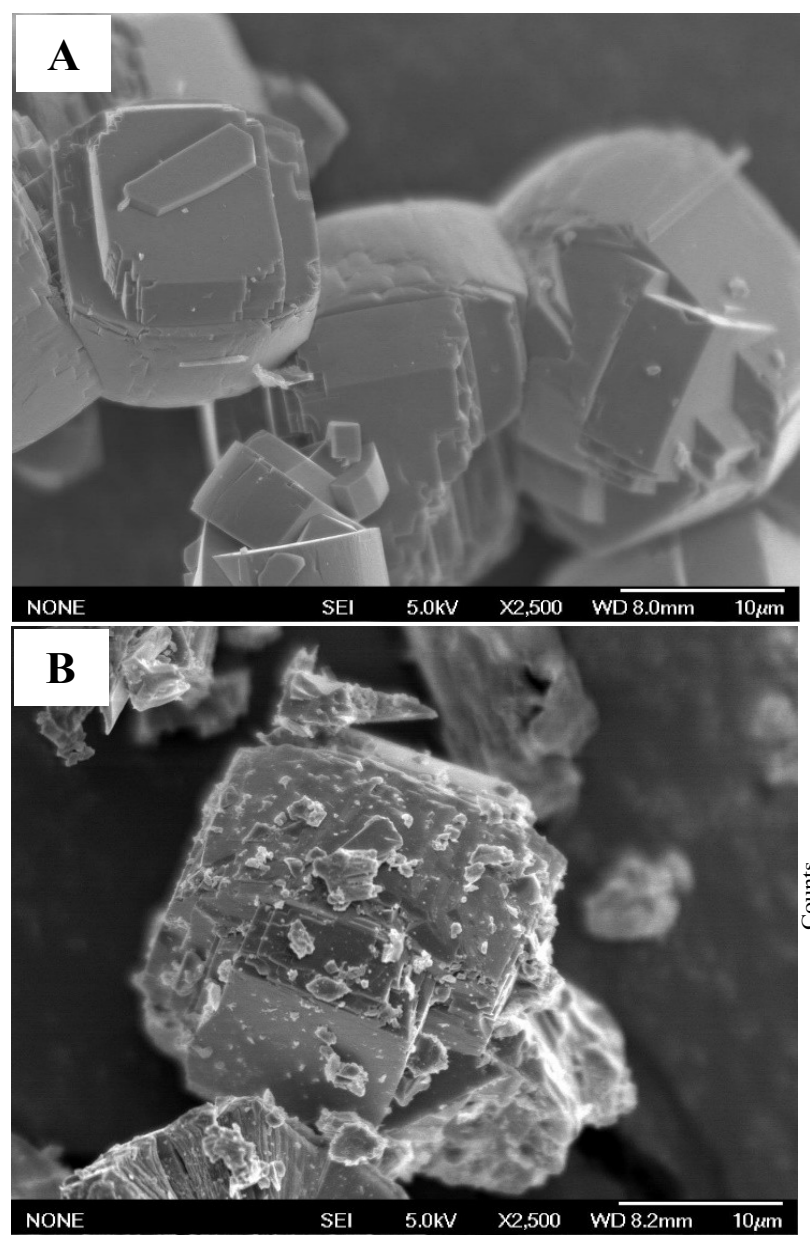

${ }^{\circ} \mathrm{C}$, the $\mathrm{CO}$ conversion and $\mathrm{CH}_{4}$ yield followed order of: Rh/mZSM5 > Co/mZSM5 > Pd/mZSM5 $>\mathrm{Zn} / \mathrm{mZSM} 5$. Only low CO conversion was obtained for bare mZSM5 (not shown). It should be noted that the presence of small amount $\mathrm{CO}_{2}$ as the side product of the methanation reaction. This is due to the co-occurrence of methanation reaction with the accompanying of water-gas shift reaction (WGSR). Overall, the most active catalyst was Rh/mZSM5, while the poorest catalyst was Zn/mZSM5. This result can be explained by the high dispersion of $\mathrm{Rh}$ on the mZSM5 support as evidenced by $\mathrm{XRD}$ and pore size distribution analysis. On the contrary, Zn metal showed poor dispersion and gave an adverse effect on the methanation activity. Besides, Co metal favored water-gas shift reaction as demonstrated by the presence of the highest amount of $\mathrm{CO}_{2}$. Moreover, the low catalytic activity of Pd/mZSM5 may be due to the low surface area as consequences from the blockage of the pores as shown by $\mathrm{N}_{2}$ physisorption analysis. The results presented the variation of metals loaded on mZSM5 will demonstrated different physicochemical properties
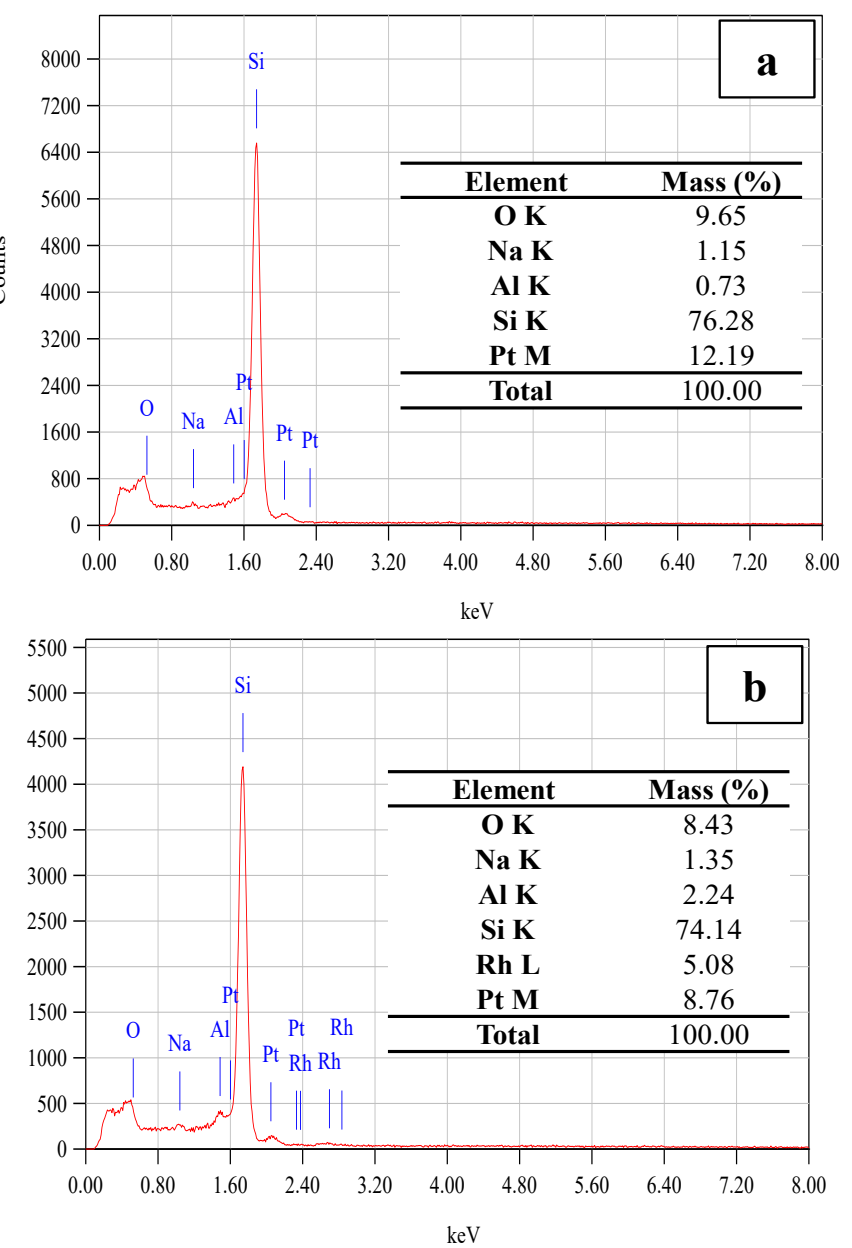

Figure 5. FESEM images and EDX analysis of (A,a) mZSM5 and (B,b) Rh/mZSM5. 
and lastly affected the $\mathrm{CO}$ methanation activity of the catalysts. We correlated the relationship of catalytic activity with properties of the catalyst (crystal structure, textural properties and structural properties), but no obvious trends were seen. Generally, the role of metals is used to dissociate $\mathrm{H}_{2}$. But, to catalyze the reaction of $\mathrm{CO}$ and $\mathrm{H}_{2}$ to form $\mathrm{CH}_{4}$, surface sites of mZSM5 that bind and activate $\mathrm{CO}$ need to be co-exist and cooperate with metal sites for dissociation of $\mathrm{H}_{2}$. Therefore, the synergistic phenomenon between metal-support is very crucial. The Rh promotional effect towards catalytic performance could be combination results of all the properties and formation of more available active sites ( $\mathrm{Rh}$ metal for $\mathrm{H}_{2}$ dissociation and mZSM5 for $\mathrm{CO}$ adsorption and interactions). Moreover, the synergistic effect of both Rh metal and ZSM5 support could be responsible for this enhancement $[13,35,36]$. The good performance of $\mathrm{Rh} / \mathrm{mZSM} 5$ in $\mathrm{CO}$ methanation could be attributed to a synergy between well dispersed Rh metal, large surface area and suitable micro-mesoporosity of mZSM5 support. However, this synergistic effect needs to be further clarification in the future work. In the recent study of Kim et al. [37], the high methanation activity of $\mathrm{Ru} / \mathrm{TiO}_{2}$ catalyst have been reported, which simply governed by "synergy" interaction of $\mathrm{Ru}$ and $\mathrm{TiO}_{2}$ support (in anatase and rutile phase), and further led to formation of more dispersed and active $\mathrm{Ru}$ species.

The improvement of the catalyst in term of catalytic activity with the introduction of metals onto supporting material was also reported in the previous literatures [38-44]. Panagiotopoulou et al. [38] reported the apparent activation energy and products selectivity in the solo- or co-methanation of $\mathrm{CO} / \mathrm{CO}_{2}$ were de-
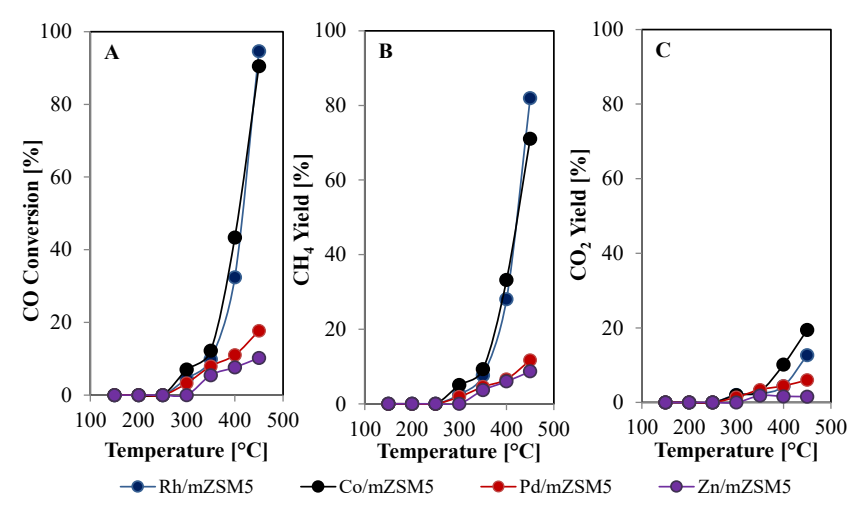

Figure 6. The catalytic performance of the catalysts. (A) $\mathrm{CO}$ conversion, (B) $\mathrm{CH}_{4}$ yield, and (C) $\mathrm{CO}_{2}$ yield. pended on the nature of the $\mathrm{Ru}, \mathrm{Rh}, \mathrm{Pt}, \mathrm{Pd}$ metallic phase. Besides, Tada et al. [39] evaluated the effect of $\mathrm{CO}$ conversion activity and products selectivity with the introduction of secondary metals (Ni, Co, Fe, La, K, Ni-La) onto $\mathrm{Ru} / \mathrm{TiO}_{2}$. They found that $\mathrm{CO}$ methanation activity was significantly affected with the addition of $\mathrm{La}$ as secondary metal on $\mathrm{Ru}$ species for improving the electron density and further facilitated CO bond dissociation. Aziz et al. [40] studied a series of 12 metal-based mesostructured silica nanoparticles (MSN) catalysts on $\mathrm{CO}_{2}$ methanation. The active sites that are responsible for this methanation reaction are basic metallic surface centers and/or oxygen vacancy sites. Miyao et al. [41] reported that the enhancement in $\mathrm{CO}$ methanation activity was observed after the addition of vanadium to the $\mathrm{Ni} / \mathrm{Al}_{2} \mathrm{O}_{3}$ catalyst with inhibition of water-gas shift reaction activity. Bacariza et al. [42] investigated the study of magnesium-promoted on Ni-based USY zeolites in $\mathrm{CO}_{2}$ methanation. The results showed that lower content of $\mathrm{Mg}$ improved the methanation activity by enhanced $\mathrm{Ni}$ particles dispersion and $\mathrm{CO}_{2}$ activation. Cao et al. [43] favored CO methanation of KIT-6 zeolite at low reaction temperature by $\mathrm{Ni}$ and $\mathrm{V}$ surface modification. They stated that the CO dissociation was improved by electron transferring from $\mathrm{V}$ species to $\mathrm{Ni}^{0}$ and the enhancement in $\mathrm{H}_{2}$ uptake and $\mathrm{Ni}$ dispersion is attributed to the presence of suitable $\mathrm{V}$ amount. The enhancement of La promoted $\mathrm{Ni}$ supported on Y- and Beta- zeolites towards $\mathrm{CO}_{2}$ methanation activity was study by Quindimil et al. [44]. The introduction of La promoter increased the surface basicity, $\mathrm{Ni}$ dispersion and $\mathrm{CO}_{2}$ adsorption capacity of the zeolites. Based on previous literatures, the enhancement in activity was dependent on the intrinsic essence of the metallic phase, which affected the activation and dissociation of $\mathrm{CO} / \mathrm{CO}_{2}$, and further accelerate the methanation activity accompanied with inhibiting the side reactions.

\section{Conclusions}

A series of metal-based mesoporous ZSM5 catalysts (Rh/mZSM5, Co/mZSM5, Pd/mZSM5, and Zn/mZSM5) prepared using dual templating and conventional incipient wetness impregnation method were tested towards $\mathrm{CO}$ methanation. The XRD results confirmed the successfully synthesized of ZSM5 support and the loaded metals were in the form of metal oxides. The nitrogen physisorption results showed that all metal-promoted mZSM5 possessed both micropores and mesopores. Co- 
existing of both micro-mesoporosity in ZSM5 gave an impact on the catalytic activity of $\mathrm{CO}$ methanation. At $450{ }^{\circ} \mathrm{C}$, the catalytic performance of $\mathrm{CO}$ methanation arranged in the sequence of Rh/mZSM5 > Co/mZSM5 > $\mathrm{Pd} / \mathrm{mZSM} 5>\mathrm{Zn} / \mathrm{mZSM} 5$. The Rh/mZSM5 showed the best performance with $\mathrm{CO}$ conversion $=95 \%$ and $\mathrm{CH}_{4}$ yield $=82 \%$. While, $\mathrm{Zn} / \mathrm{mZSM} 5$ is the poorest catalyst with $\mathrm{CO}$ conversion $=10 \%$ and $\mathrm{CH}_{4}$ yield $=9 \%$. This study clearly showed the improvement in the $\mathrm{CO}$ methanation activity was significantly governed by the effect of metal promoters on mZSM5. The good activity in Rh/mZSM5 probably due to the synergistic effect of both $\mathrm{Rh}$ metal and mZSM5 support.

\section{Acknowledgements}

The authors acknowledge the support through Young Researcher Incentive Grant (GGPM-2017-075) by Universiti Kebangsaan Malaysia and Post-doctoral Research Grant (No. 04E07) by Universiti Teknologi Malaysia.

\section{References}

[1] Jia, C., Gao, J., Li, J., Gu, F., Xu, G., Zhong, Z., Su, F. (2013). Nickel Catalysts Supported on Calcium Titanate for Enhanced CO Methanation. Catalysis Science \& Technology, 3: 490-499.

[2] Tao, M., Xin, Z., Meng, X., Bian, Z., Lv, Y. (2017). Highly Dispersed Nickel within Mesochannels of SBA-15 for CO Methanation with Enhanced Activity and Excellent Thermostability. Fuel, 188: 267-276.

[3] Liu, Q., Gu, F., Lu, X., Liu, Y., Li, H., Zhong, Z., Xu, G., Su, F. (2014). Enhanced Catalytic Performance of $\mathrm{Ni} / \mathrm{Al}_{2} \mathrm{O}_{3}$ Catalyst via Addition of $\mathrm{V}_{2} \mathrm{O}_{3}$ for CO Methanation. Applied Catalysis A: General, 488: 37-47.

[4] Gong, D., Li, S., Guo, S., Tang, H., Wang, H., Liu, Y. (2018). Lanthanum and Cerium Comodified $\mathrm{Ni} / \mathrm{SiO}_{2}$ Catalyst for CO Methanation from Syngas. Applied Surface Science, 434: 351-364.

[5] Bian, Z., Xin, Z., Meng, X., Tao, M., Lv, Y., $\mathrm{Gu}$, J. (2017). Effect of Citric Acid on the Synthesis of CO Methanation Catalysts with High Activity and Excellent Stability. Industrial \& Engineering Chemistry Research, 56(9): 2383-2392.

[6] Li, P., Zhu, M., Dan, J., Kang, L., Lai, L., Cai, X., Zhang, J., Yu, F., Tian, Z., Dai, B. (2017). Two-dimensional Porous $\mathrm{SiO}_{2}$ Nanomesh Supported High Dispersed Ni Nanoparticles for CO Methanation. Chemical Engineering Journal, 326: $774-780$.
[7] Arandiyan, H., Kasaeian, G., Nematollahi, B., Wang, Y., Sun, H., Bartlett, S., Dai, H., Rezaei, M. (2018). Self-assembly of Flowerlike $\mathrm{LaNiAlO}_{3}$-supported Nickel Catalyst for CO Methanation. Catalysis Communications, 115: 40-44.

[8] Odedairo, T., Balasamy, R.J., Al-Khattaf, S. (2011). Influence of Mesoporous Materials Containing ZSM-5 on Alkylation and Cracking Reactions. Journal of Molecular Catalysis A: Chemical, 345: 21-36.

[9] Zhang, C., Wu, Q., Lei, C., Pan, S., Bian, C., Wang, L., Meng, X., Xiao, F. (2017). Solvent free and Mesoporogen-free Synthesis of Mesoporous Aluminosilicate ZSM-5 Zeolites with Superior Catalytic Properties in Methanol-to-olefins. Industrial \& Engineering Chemistry Research, 56(6): 1450-1460.

[10] Zhuang, S., Hu, Z.H., Huang, L., Qin, F., Huang, Z., Sun, C., Shen, W., Xu, H. (2018). Synthesis of ZSM-5 Catalysts with Tunable Mesoporosity by Ultrasound-assisted Method: A Highly Stable Catalyst for Methanol to Propylene. Catalysis Communications, 114: 2832.

[11] Li, H., Dong, L., Zhao, L., Cao, L., Gao, J., Xu, C. (2017). Enhanced Adsorption Desulfurization Performance over Mesoporous ZSM-5 by Alkali Treatment. Industrial \& Engineering Chemistry Research, 56(14): 3813-3821.

[12] Wang, Y., Du, T., Song, Y., Che, S., Fang, X., Zhou, L. (2017). Amine-functionalized Mesoporous ZSM-5 Zeolite Adsorbents for Carbon Capture. Solid State Sciences, 73: 2735.

[13] Guo, X., Traitangwong, A., Hu, M., Zuo, C., Meeyoo, V., Peng, Z., Li, C. (2018). Carbon Dioxide Methanation over Nickel-based Catalysts Supported on Various Mesoporus Material. Energy Fuels, 32(3): 3681-3689.

[14] Cao, H., Zhang, J., Guo, C., Chen, J.G., Ren, X. (2017). Highly Dispersed Ni Nanoparticles on 3D-mesoporous KIT-6 for CO Methanation: Effect of Promoter Species on Catalytic Performance. Chinese Journal of Catalysis, 38: 1127-1137.

[15] Liu, Q., Yang, H., Dong, H., Zhang, W., Bian, B., He, Q., Yang, J., Meng, X., Tian, Z., Zhao,G. (2018). Effect of Preparation Method and $\mathrm{Sm}_{2} \mathrm{O}_{3}$ Promoter on $\mathrm{CO}$ Methanation by a Mesoporous NiO- $\mathrm{Sm}_{2} \mathrm{O}_{3} / \mathrm{Al}_{2} \mathrm{O}_{3}$ Catalyst. New Journal of Chemistry, 42: 13096-13106.

[16] Lv, Y., Xin, Z., Meng, X., Tao, M., Bian, Z. (2018). Ni Based Catalyst Supported on KIT6 Silica for CO Methanation: Confinement Effect of Three Dimensional Channel on $\mathrm{NiO}$ and Ni Particles. Microporous and Mesoporous Materials, 262: 89-97. 
[17] Panagiotopoulou, P. (2017). Hydrogenation of $\mathrm{CO}_{2}$ over Supported Noble Metal Catalysts. Applied Catalysis A: General, 542: 63-70.

[18] Zhang, C., Liu, B., Wang, Y., Zhao, L., Zhang, J., Zong, Q., Gao, J., Xu, C. (2017). The Effect of Cobalt Promoter on the CO Methanation Reaction over $\mathrm{MoS}_{2}$ Catalyst: A Density Functional Study. RSC Advances, 7: 11862-11871.

[19] Martin, N.M., Hemmingsson, F., Wang, X., Merte, L.R., Hejral, U., Gustafson, J., Skoglundh, M., Meira, D.M., Dippel, A., Gutowski, O., Bauer, M., Carlsson, P. (2018). Stucture-function Relationship during $\mathrm{CO}_{2}$ Methanation over $\mathrm{Rh} / \mathrm{Al}_{2} \mathrm{O}_{3}$ and $\mathrm{Rh} / \mathrm{SiO}_{2}$ Catalysts at Atmospheric Pressure Conditions. Catalysis Science \& Technology, 8: 2686-2696.

[20] Barrientos, J., Gonzalez, N., Boutonnet, M., Järås, S. (2017). Deactivation of $\mathrm{Ni} / \gamma-\mathrm{Al}_{2} \mathrm{O}_{3}$ Catalysts in CO Methanation: Effect of Zr, $\mathrm{Mg}, \mathrm{Ba}$ and $\mathrm{Ca}$ Oxide Promoters. Topics in Catalysis, 60(17-18): 1276-1284.

[21] Teh, L.P., Triwahyono, S., Jalil, A.A., Mukti, R.R., Aziz, M.A.A., Shishido, T. (2015). Mesoporous ZSM5 Having Both Intrinsic Acidic and Basic Sites for Cracking and Methanation. Chemical Engineering Journal, 270: 196-204.

[22] Mulukutla, R.S., Shido, T., Asakura, K., Kogure, T., Iwasawa, Y. (2002). Characterization of Rhodium Oxide Nanoparticles in MCM-41 and Their Catalytic Performances for NO-CO Reactions in Excess $\mathrm{O}_{2}$. Applied Catalysis A: General, 228: 305-314.

[23] Vita, A., Italiano, C., Pino, L., Laganà, M., Recupero, V. (2017). Hydrogen-rich Gas Production by Steam Reforming of $\mathrm{n}$-Dodecane. Part II: Stability, Regenerability and Sulfur Poisoning of Low Loading Rh-based Catalyst. Applied Catalysis B: Environmental, 218: 317326.

[24] Li, B., Zhu, Y., Jin, X. (2015). Synthesis of Cobalt-containing Mesoporous Catalysts using the Ultrasonic-assisted "pH-Adjusting" Method: Importance of Cobalt species in Styrene Oxidation. Journal of Solid State Chemistry, 221: 230-239.

[25] Díez-Ramírez, J., Sánchez, P., Kyriakou, V., Zafeiratos, S., Marnellos, G.E., Konsolakis, M., Dorado, F. (2017). Effect of Support Nature on the Cobalt-catalyzed $\mathrm{CO}_{2}$ Hydrogenation. Journal of $\mathrm{CO}_{2}$ Utilization, 21: 562-571.

[26] Yoshida, H., Nakajima, T., Yazawa, Y., Hattori, T. (2007). Support Effect on Methane Combustion over Palladium Catalysts. Applied Catalysis B: Environmental, 71: 70-79.

[27] Cai, Y., Chen, X., Wang, Y., Qiu, M., Fan, Y. (2015). Fabrication of Palladium-titania Nanofiltration Membranes via a Colloidal Sol-gel
Process. Microporous and Mesoporous Materials, 201: 202-209.

[28] Adams, E.C., Skoglundh, M., Folic, M., Bendixen, E.C., Gabrielsson, P., Carlsson, P. (2015). Ammonia Formation over Supported Platinum and Palladium Catalysts. Applied Catalysis B: Environmental, 165: 10-19.

[29] Hairom, N.H.H., Mohammad, A.W., Kadhum, A.A.H. (2015). Influence of Zinc Oxide Nanoparticles in the Nanofiltration of Hazardous Congo Red Dyes. Chemical Engineering Journal, 260: 907-915.

[30] Teh, L.P., Triwahyono, S., Jalil, A.A., Mamat, C.R., Sidik, S.M., Fatah, N.A.A., Mukti, R.R., Shishido, T. (2015). Nickel-promoted Mesoporous ZSM5 for Carbon Monoxide Methanation. RSC Advances, 5: 6465164660 .

[31] Belharouak, I., Pol, V.G. (2012). Advances in Iorganic Phosphate Materials. John Wiley \& Sons. 175-185.

[32] Bautista, F.M., Campelo, J.M., Garcia, A., Leon, R.M., Luna, D., Marinas, J.M., Romero, A.A., Navio, J.A., Maclas, M. (1999). Stucture, Textural, Acidity and Catalytic Performance of $\mathrm{AIPO}_{4}$-Caesium Oxide Catalysts in 2-Methyl-3-Butyn-2-ol Conversion. Journal of Materials Chemistry, 9: 827-835.

[33] Hassaninejad-Darzi, S.K. (2015). Fabrication of a Non-enzymatic Ni(II) Loaded ZSM-5 Nanozeolite and Multi-walled Carbon Nanotubes Paste Electrode as a Glucose Electrochemical Sensor. RSC Advances, 5: 105707105718 .

[34] Hosseinpour, M., Golzary, A., Saber, M., Yoshikawa, K. (2017). Denitrogenation of Biocrude Oil from Algal Biomass in High Temperature Water and Formic Acid Mixture over H+ZSM-5 Nanocatalyst. Fuel, 206: 628637.

[35] Park, J.N., McFarland, E.W. (2009). A Highly Dispersed $\mathrm{Pd}-\mathrm{Mg} / \mathrm{SiO}_{2}$ Catalyst Active for Methanation of $\mathrm{CO}_{2}$. Journal of Catalysis, 266: 92-97.

[36] Le, M.C., Van, K.L., Nguyen, T.H.T., Nguyen, N.H. (2017). The Impact of Ce-Zr Addition on Nickel Dispersion and Catalytic Behavior for $\mathrm{CO}_{2}$ Methanation of Ni/AC Catalyst at Low Temperature. Journal of Chemistry, 2017: Article ID 4361056.

[37] Kim, A., Debecker, D.P., Devred, F., Dubois, V., Sanchez, C., Sassoye, C. (2018). $\mathrm{CO}_{2}$ Methanation on $\mathrm{Ru} / \mathrm{TiO}_{2}$ Catalysts: On the Effect of Mixing Anatase and Rutile $\mathrm{TiO}_{2}$ Supports. Applied Catalysis B: Environmental, 220: 615-625.

[38] Panagiotopoulou, P., Kondarides, D.I., Verykios, X.E. (2008). Selective Methanation 
of CO over Supported Noble Metal Catalysts: Effects of the Nature of the Metallic Phase on Catalytic Performance. Applied Catalysis A: General, 344: 45-54.

[39] Tada, S., Kikuchi, R., Takagaki, A., Sugawara, T., Oyama, S.T., Satokawa, S. (2014). Effect of Metal Addition to $\mathrm{Ru} / \mathrm{TiO}_{2}$ Catalyst on Selective CO Methanation. Catalysis Today, 232: 16-21.

[40] Aziz, M.A.A., Jalil, A.A., Triwahyono, S., Sidik, S.M. (2014). Methanation of Carbon Dioxide on Metal-promoted Mesostructured Silica Nanoparticles. Applied Catalysis A: General, 486: 115-122.

[41] Miyao, T., Sakurabayashi, S., Shen, W., Higashiyama, K., Watanabe, M. (2015). Preparation and Catalytic Activity of a Mesoporous Silica-coated Ni-alumina-based Catalyst for Slective CO Methanation. Catalysis Communications, 58: 93-96.
[42] Bacariza, M.C., Graça, I., Bebiano, S.S., Lopes, J.M., Henriques, C. (2017). Magnesium as Promoter of the $\mathrm{CO}_{2}$ Methanation on Ni-based USY Zeolites. Energy Fuels, 31(9): 9776-9789.

[43] Cao, H., Zhang, J., Guo, C., Chen, J.G., Ren, X. (2017). Modifying Surface Properties of KIT-6 Zeolite with $\mathrm{Ni}$ and V for Enhancing Catalytic CO Methanation. Applied Surface Science, 426: 40-49.

[44] Quindimil, A., Torre, U.D., Pereda, B., González-Marcos, J.A., González-Velasco, J.R. (2018). Ni Catalysts with La as Promoter Supported over Y- and Beta- Zeolites for $\mathrm{CO}_{2}$ Methantion. Applied Catalysis B: Environmental, 238: 393-403.

Selected and Revised Papers from The $4^{\text {th }}$ International Conference of Chemical Engineering \& Industrial Biotechnology (ICCEIB 2018) (http://icceib.ump.edu.my/index.php/en/) (Universiti Malaysia Pahang, by 1st_2nd August 2018) after Peer-reviewed by Scientific Committee of ICCEIB 2018 and Peer-Reviewers of Bulletin of Chemical Reaction Engineering \& Catalysis 